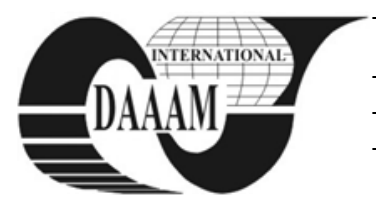

Annals of DAAAM for 2011 \& Proceedings of the 22nd International DAAAM Symposium, Volume 22, No. 1, ISSN 1726-9679 ISBN 978-3-901509-83-4, Editor B. Katalinic, Published by DAAAM International, Vienna, Austria, EU, 2011 Make Harmony between Technology and Nature, and Your Mind will Fly Free as a Bird Annals \& Proceedings of DAAAM International 2011

\title{
FUZZY SYSTEM FOR CONTROL OF A CNC CUTTING MACHINE
}

\author{
TIRIAN, G[elu] O[vidiu]
}

\begin{abstract}
This paper work is meant to come up with a complex system based on fuzzy logics for automatic selection of oxygen pressure CNC in a tin plate cutting machine. Thickness and type of fuzzy system analyzes and automatically adjusts the oxygen pressure plate and amperage needed, thereby eliminating human operator error in decision making
\end{abstract}

Key words: fuzzy system, cutting, control, machine, pressure

\section{INTRODUCTION}

Nowadays, working with machine tools is one of the most important activities to support industrial development. Numerically controlled machine tools and machines are called CNC (Computer Numerically Controlled). Numerical control process consist of an unceasing "supply" of a programmable controller specially designed with a set of instructions (made up of letters and numbers) so that it can be controlled movements of a machine - tool (Mareş, 2001).

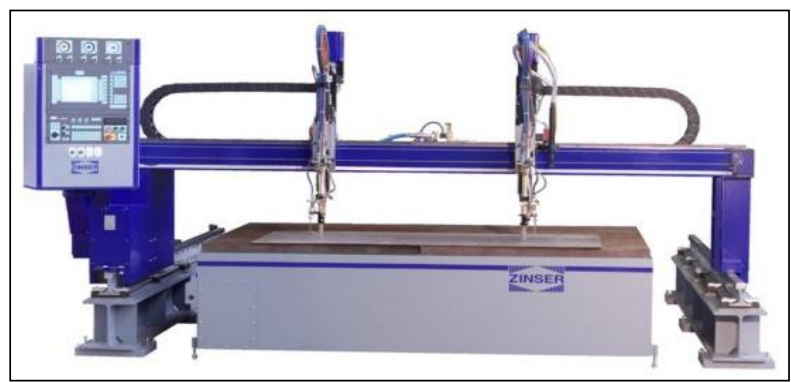

Fig. 1. Zinser CNC 2010 machine

Sick OD VALUE laser sensors are electro-optical sensors that can measure distances on flat surfaces or reflective objects, using a particular process avoiding any direct contact. The distance to an object is detected by the principle of triangulation. A directed laser beam makes up a point on the object subject to measurement. The image of the point is reflected in a position detector and it converts the position into the distance to the object (Breaz, 2001).

\section{PRINCIPLE OF OPERATION}

For tin plate cutting machine Zinser CNC 2010 we have shapes up a complex system which increases accuracy and cutting quality based on fuzzy logic. This device replaces the human operator in selecting the oxygen pressure and amperage right choice for different types of tin plate and its various thicknesses.

Sheet thickness is automatically taken by the differential sensor mounted on top rail of the car. The second signal on the type plate is determined by a human operator, and it is selected from a button on the center console of the Zinser 2010 machine.

The fuzzy system is applied into two analog signals, with values between $\left(\begin{array}{lll}0 & \ldots & 5\end{array}\right) \mathrm{V}$, whose value depends on the thickness of the board type. Based on the two applied signals and to its processing program implemented within the fuzzy controller - as types of rules for processing - at the analog output we obtain two continuous tension signals, in the range $(0$ ... 5) V (Tirian, 2009).

To process the two signals is numerical and enclosed within a complex system based on fuzzy logic. The set of rules we use is determined by a group of human experts and could be changed at any time (Precup, 1999) thus, ensuring the system to adapt to any operating condition of the real CNC machine.

\section{DESIGNING OF THE FUZZY CONTROLLER}

Figure no. 2 describes the block diagram of the fuzzy controller.

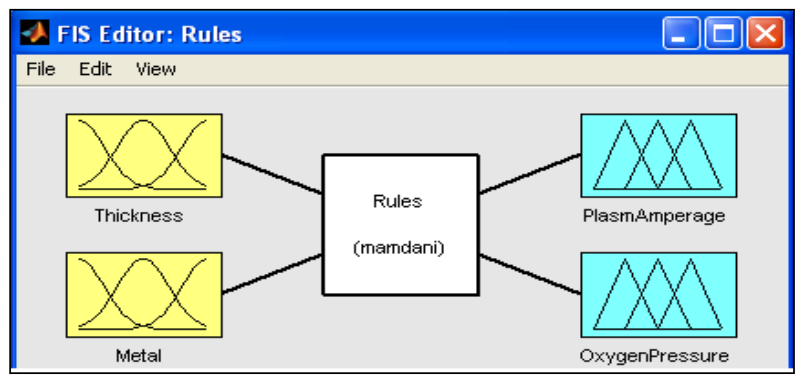

Fig. 2. Block diagram of a fuzzy controller

We have designed the fuzzy controller using Matlab. We have also established the linguistic terms (for both input and output), the belonging functions, and the rule base.

A. Information input size

We have considered the foloowing input size:

A1. For tin plate thickness :

\begin{tabular}{|l|l|l|}
\hline $\begin{array}{c}\text { Linguistic values } \\
\text { "tin plate } \\
\text { thickness" }\end{array}$ & \multicolumn{1}{|c|}{$\begin{array}{c}\text { Variation range } \\
\text { [mm] }\end{array}$} & $\begin{array}{c}\text { Discussion } \\
\text { "universe" [\%] }\end{array}$ \\
\hline Very Low & $1 \div 5$ & $0 \div 0.0075$ \\
\hline Low & $5 \div 10$ & $0,05 \div 0,15$ \\
\hline Medium & $10 \div 15$ & $0,125 \div 0,225$ \\
\hline High & $15 \div 40$ & $0,20 \div 0,60$ \\
\hline Very High & $40 \div 150$ & $0,55 \div 1$ \\
\hline
\end{tabular}

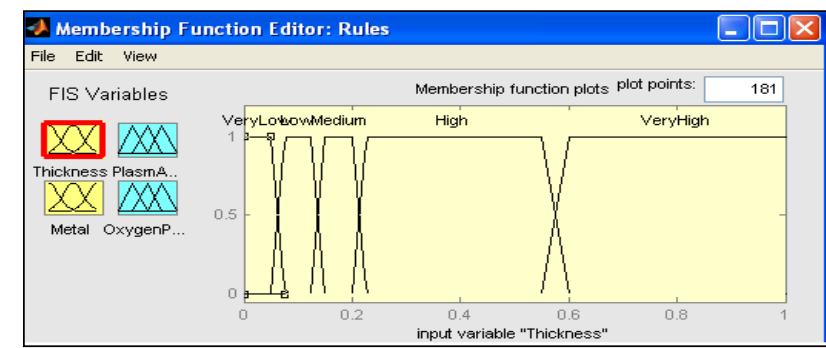

Fig. 3. Belonging function representation of ,tin plate thickness" 
A2. For material type of the plate:

\begin{tabular}{|l|l|l|}
\hline $\begin{array}{c}\text { Linguistic values } \\
\text { "material type" }\end{array}$ & Variation domaine & $\begin{array}{c}\text { Discussion } \\
\text { "universe" [\%] }\end{array}$ \\
\hline stainless steel & & $0 \div 50$ \\
\hline steel & & $50 \div 100$ \\
\hline
\end{tabular}

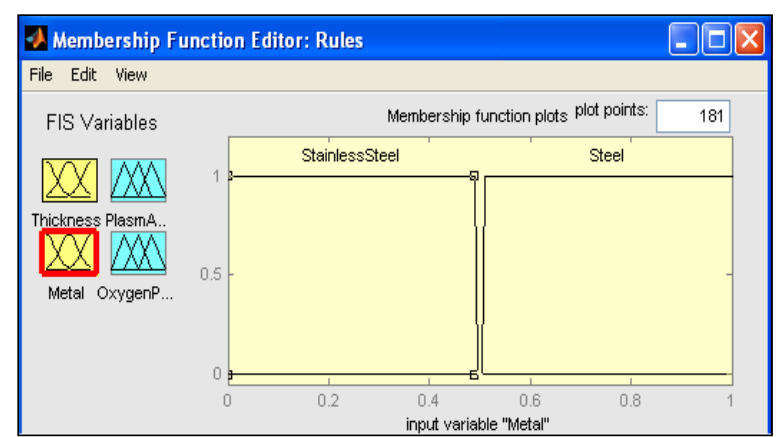

Fig. 4. Membership function of „tin plate thickness”

B. Input size information (control)

We have considered the following output size:

B1. For amperage control:

\begin{tabular}{|l|l|l|}
\hline $\begin{array}{c}\text { Linguistic values } \\
\text { "Plasm Amperage" }\end{array}$ & $\begin{array}{c}\text { Variation domain } \\
\text { [A] }\end{array}$ & $\begin{array}{c}\text { Discussion } \\
\text { "universe" [\%] }\end{array}$ \\
\hline zero & 0 & 0 \\
\hline low & 45 & 0,35 \\
\hline medium & 90 & 0,69 \\
\hline high & 130 & 1 \\
\hline
\end{tabular}

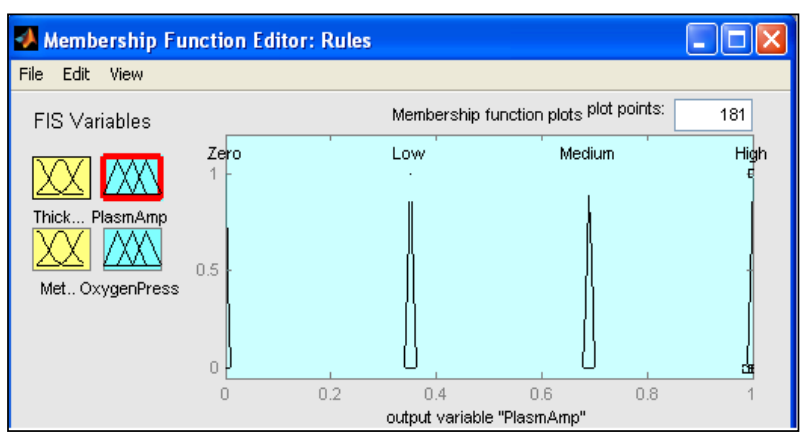

Fig. 5. Membership function of "Plasm Amperage"

B2. For oxygen presure control:

\begin{tabular}{|l|l|l|}
\hline $\begin{array}{c}\text { Linguistic values } \\
\text { "Oxygen Pressure" }\end{array}$ & $\begin{array}{c}\text { Variation domain } \\
\text { [atm] }\end{array}$ & $\begin{array}{c}\text { Discussion } \\
\text { "universe" [\%] }\end{array}$ \\
\hline Zero & 0 & $0 \div 0.08$ \\
\hline Low & $3 \div 4$ & $0.1 \div 0.66$ \\
\hline Medium & $4 \div 5$ & $0.6 \div 0.83$ \\
\hline High & $5 \div 6$ & $0.75 \div 0.1$ \\
\hline
\end{tabular}

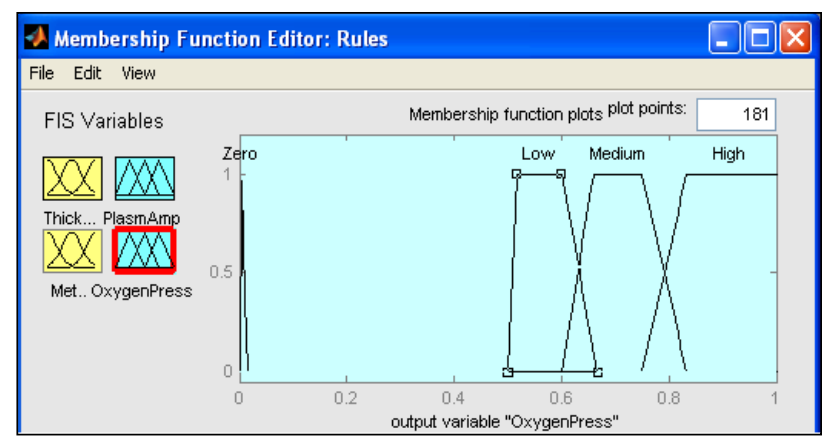

Fig. 6. Membership function of "Oxygen Pressure"

\section{Control rules (inference)}

Rules have been established for practical reasons, after consulting the literature and experts in the field.

Figure 7 describe the inference table that connects fuzzy input variables to output variables - described above - using the max-min inference method. The process on de-fuzzying is based on the singleton weight centers due to its major advantage, namely for small processing imperative condition for the operation of Fuzzy controller in real time. Therefore, for practical application review, we have been established the singleton type membership functions corresponding to linguistic term "control" of the output quantity. It is very common in practice to use it along with the max-min inference method and the above mentioned de-fuzzying method, and the results is an outstanding performance of control systems (Tirian, 2009).

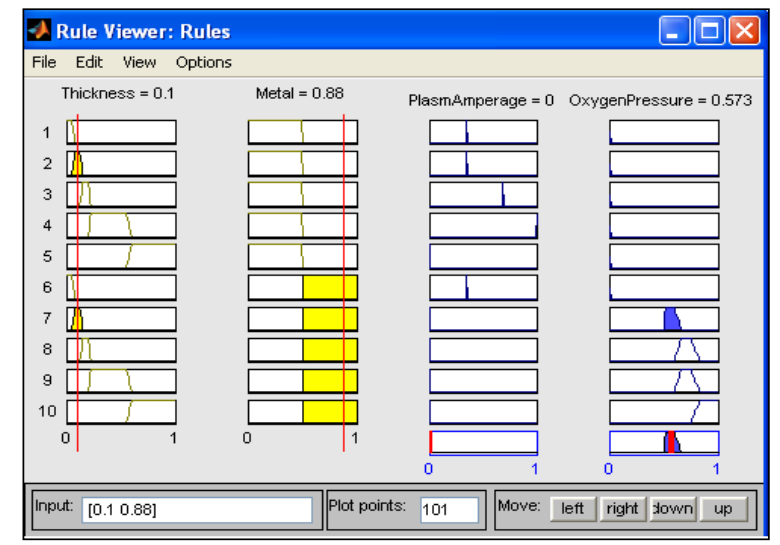

Fig. 7. Inferrence table

It is noted that in case of the "Sheet thickness" input sizes (small) and "Material type" (steel) the relay controls the cutting oxygen machine and it switches it to an output of 0.573 , corresponding to a pressure slightly big than 3 atmospheres.

\section{CONCLUSIONS}

This paper proposes a complex device control board of a CNC Zinser cutting machine. The proposed system has several advantages over other existing systems on the market. These advantages are: reduced human operator errors in decisions making referring to adjusting amperage and oxygen pressure; adaptability to any real situation by modifying the rules base, low price.

\section{REFERENCES}

Breaz R. (2001). Research Contributions Precision Machine Tools and Assessment for Compensation Errors Techniques, PhD Thesis, Cluj Napoca, 2001

Mareş F. (2001). „Control and commands elements”, Editure Negro, Galaţi. Romania, 2001

Precup, R.E \& Preitl, Şt. (1999). Fuzzy Controllers, Editure Academic „Horizons”, pp. 123-128, ISBN: 973-9400-61-2, Timişoara, Romania

Tirian, G.O., Anghel, S. \& Pinca C. (2009). Control System of the Continuous Casting Process for Cracks Removal, $5^{\text {th }}$ International Symposium on Applied Computational Intelligence and Informatics, May 28-29, pp. 265-269, ISBN: 978-1-4244-4478-6, Timisoara, Romania, 2009

Tirian G.O., O.Prostean, S. Rusu-Anghel, Pinca B. C, D.Cristea (2009). Fuzzy System for Implementing Cracks Control During Continuous Casting, Annals of DAAAM \&Proceedings of the 20th International Symposium, Volume 20, No.1, ISSN 1726-9679, ISBN 978-3-90150970-4, pp.1661-1662, 25-28th November, Vienna, Austria, 2009 